\title{
Chromatin-bound NLS proteins recruit membrane vesicles and nucleoporins for nuclear envelope assembly via importin- $\alpha / \beta$
}

Quanlong $\mathrm{Lu}^{1,{ }^{*}}$, Zhigang Lu ${ }^{1, *}$, Qinying Liu ${ }^{1,{ }^{*}}$, Li Guo ${ }^{1}$, He Ren ${ }^{1}$, Jingyan Fu${ }^{1}$, Qing Jiang ${ }^{1}$, Paul R Clarke ${ }^{2}$, Chuanmao Zhang ${ }^{1}$

${ }^{1}$ State Key Laboratory of Bio-membrane and Membrane Biotechnology and Key Laboratory of Cell Proliferation and Differentiation of Ministry of Education, College of Life Sciences, Peking University, Beijing 100871, China; ${ }^{2}$ Division of Cancer Research, Jacqui Wood Cancer Centre, Ninewells Hospital and Medical School, University of Dundee, DD1 9SY, Scotland, UK

The mechanism for nuclear envelope (NE) assembly is not fully understood. Importin- $\beta$ and the small GTPase Ran have been implicated in the spatial regulation of $\mathrm{NE}$ assembly process. Here we report that chromatin-bound NLS (nuclear localization sequence) proteins provide docking sites for the NE precursor membrane vesicles and nucleoporins via importin- $\alpha$ and $-\beta$ during $\mathrm{NE}$ assembly in Xenopus egg extracts. We show that along with the fast recruitment of the abundant NLS proteins such as nucleoplasmin and histones to the demembranated sperm chromatin in the extracts, importin- $\alpha$ binds the chromatin NLS proteins rapidly. Meanwhile, importin- $\beta$ binds cytoplasmic NE precursor membrane vesicles and nucleoporins. Through interacting with importin- $\alpha$ on the chromatin NLS proteins, importin- $\beta$ targets the membrane vesicles and nucleoporins to the chromatin surface. Once encountering RanGTP on the chromatin generated by RCC1, importin- $\beta$ preferentially binds Ran-GTP and releases the membrane vesicles and nucleoporins for $\mathrm{NE}$ assembly. $\mathrm{NE}$ assembly is disrupted by blocking the interaction between importin- $\alpha$ and NLS proteins with excess soluble NLS proteins or by depletion of importin- $\beta$ from the extract. Our findings reveal a novel molecular mechanism for NE assembly in Xenopus egg extracts.

Keywords: nuclear assembly; nucleoplasmin; Ran GTPase; nuclear pore complex; importin

Cell Research (2012) 22:1562-1575. doi:10.1038/cr.2012.113; published online 31 July 2012

\section{Introduction}

Nuclear envelope (NE) is composed of an inner and an outer nuclear membrane studded with nuclear pore complexes (NPCs) [1]. In higher eukaryotes, NE disassembles into membrane vesicles or is absorbed into the endoplasmic reticulum in early mitosis. Along with NE disassembly in mitosis, NPCs depolymerize into nucleoporins and disperse into the cytoplasm. At the end of mitosis, NE reforms around each of the two segregated daughter chromosome masses, and NPCs reassemble

*These three authors contributed equally to this work.

Correspondence: Chuanmao Zhang

Tel: +86-10-62757173; Fax: +86-10-62767246

E-mail: zhangcm@pku.edu.cn

Received 28 April 2012; revised 2 July 2012; accepted 3 July 2012; published online 31 July 2012 either on the chromatin as NE forms or NPC inserts into the NE [2-4]. The mechanism for NE assembly is still poorly understood, but can be studied in vitro using $\mathrm{Xe}$ nopus egg extracts as well as in intact cells. In Xenopus egg extracts, NE can be assembled around chromatin derived from demembranated sperm heads, which undergo decondensation once added into the extracts. Chromatin recruits the NE precursor membrane vesicles and nucleoporins to its surface to assemble an NE and the NPCs [5]. In this process, it is thought that the nucleoporin protein ELYS may play an important role in the recruitment of the other nucleoporins Nup107-160 complex onto the chromatin to initiate NPC assembly [6-13].

The small GTPase Ran regulates NE and NPC assembly, as well as nucleocytoplasmic transport and mitotic spindle formation [10, 14-21]. Chromatin-independent $\mathrm{NE}$ assembly can be induced using artificial beads coated with Ran in the extracts from Xenopus eggs or somatic 
cells $[17,18]$. This Ran-directed NE assembly process requires the Ran-GTP-binding protein importin- $\beta$ [22, $23]$. Importin- $\beta$-coated beads directly recruit NE precursor membrane vesicles and the nucleoporins [22]. Importin- $\beta^{45-462}$, a truncated importin- $\beta$ that lacks the importin- $\alpha$-binding domain but maintains the binding site for the nucleoporins, also induces NE assembly, indicating that the interaction of importin- $\beta$ with the nucleoporins is crucial for NE and NPC assembly regulated by Ran [22]. Importantly, soluble importin- $\beta^{45-462}$ blocks NE and NPC assembly around the beads either coated with Ran or full-length importin- $\beta$ [22]. Importin- $\beta$ is also necessary for the proper spatial organization of $\mathrm{NE}$ around the chromatin in the egg extracts, but excess of importin- $\beta$ inhibits NE assembly [24]. In addition, a membrane-associated fraction of importin- $\alpha$ functions in $\mathrm{NE}$ assembly [25]. Together, these findings indicate that both importin- $\alpha$ and importin- $\beta$ play roles in NE assembly. Whether these proteins collaborate to regulate NE assembly process, or they function in a similar manner as in nuclear transport of the nuclear localization signal (NLS) proteins is not known [26].

Previously, we proposed a model wherein importins act as targeting proteins to deliver nucleoporins to the chromatin through a transient interaction disrupted by chromosome-associated Ran-GTP [27]. More recently we have shown that importin- $\beta$ binds membrane-bound lamin B receptor (LBR) through its N-terminal domain to target the membrane to the chromatin surface for NE assembly both in somatic cells in vivo and in somatic cell extracts or Xenopus egg extracts in vitro [28, 29]. When exogenous LBR N-terminal domain truncate was added to the extracts to disrupt the interaction of importin- $\beta$ and LBR-bound membrane, NE assembly was blocked $[28,29]$. However, how the membrane is targeted by importin- $\beta$ remains unclear.

In this work, we show that NLS proteins and importin- $\alpha$, in addition to importin- $\beta$, play an essential role in NE assembly in Xenopus egg extracts. Because nucleoplasmin, histones and NuMA are abundant NLS proteins in the extracts [30-35], we have tested the roles of these proteins in NE assembly. We observed that these NLS proteins bind to chromatin at very early stage of $\mathrm{NE}$ assembly and may offer their NLSs as docking sites for importin- $\alpha$. Through dimerization with importin- $\alpha$, importin- $\beta$ targets its bound membrane vesicles and nucleoporins to the surface of the chromatin, thus initiating Ran-regulated NE assembly. Moreover, without chromatin, NLS proteins alone coated onto beads were able to induce Ran-regulated NE assembly, indicating that concentration of suitable NLS proteins around the chromatin may be the first step for NE assembly.

\section{Results}

Nucleoplasmin induces NE assembly in Xenopus egg extracts

Nucleoplasmin is an abundant protein in Xenopus egg extracts, while it is absent from the demembranated sperm chromatin. Once the sperm chromatin is added to egg extracts, nucleoplasmin is quickly recruited onto the chromatin $[31,36]$. To test the role for nucleoplasmin in NE assembly, we first incubated membrane-depleted high-speed supernatant (HSS) of Xenopus egg extract with sperm chromatin and found that nucleoplasmin binds to the chromatin rapidly (in $5 \mathrm{~min}$, Figure 1A and $1 \mathrm{~B})$. We also demonstrated that importin- $\alpha$ and importin- $\beta$ were recruited to the chromatin (Figure 1A). Interestingly, immunoblotting analysis indicated that importin- $\alpha$ bound to chromatin earlier than importin- $\beta$ (Figure 1B). One explanation for this observation is that importin- $\alpha$ directly binds the NLS domain of nucleoplasmin [37]. Based on this observation and the reports that importin- $\beta$ targets nucleoporins and membrane vesicles to the chromatin surface during NE assembly [22], we hypothesized that nucleoplasmin might be the docking site for importin- $\beta$-mediated membrane vesicles and nucleoporins, adapted by importin- $\alpha$ that could directly bind nucleoplasmin using its NLS-binding domain and dimerize with importin- $\beta$ using its importin- $\beta$-binding domain. To directly test this model, we established an in vitro NE assembly assay. Recombinant nucleoplasmin fused with glutathione S-transferase (GST) was immobilized onto glutathione-Sepharose or Dyna beads and the beads were incubated with Xenopus egg extracts. We predicted that this system could mimic the interaction with chromatin, and NE assembly would be organized around bead-nucleoplasmin following egg extract addition via recruitment of importin- $\beta$-mediated membrane vesicles and nucleoporins adopted by importin- $\alpha$. As predicted, we found that nucleoplasmin but not GST alone immobilized on the beads specifically induced accumulation of lipids around the beads in the egg extracts, viewed by lipophilic dye 3,3'-dihexyloxacarbocyanine (DHCC) staining (Figure 1C). Transmission electron microscopy (TEM) confirmed that the lipid accumulations were double-layered membranes with NPC-like structures (Figure 1D). These membranes completely covered the beads as evidenced by the exclusion of large molecular weight proteins from the beads (Figure 1E). By immunofluorescence light microscopy and western blotting, we demonstrated that the NPC-like structures are NPCs as they contained typical nucleoporin profiles and a nuclear lamina (Figure $1 \mathrm{~F}$ and $1 \mathrm{G}$ ). Moreover, importin- $\alpha$ and importin- $\beta$ were also associated with the 


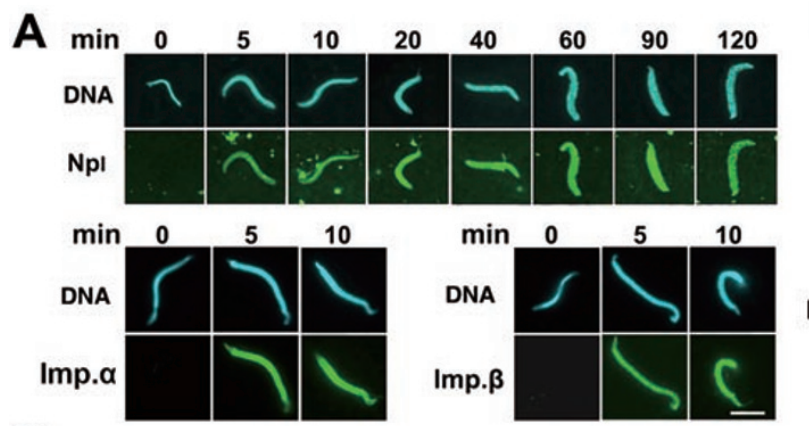

B

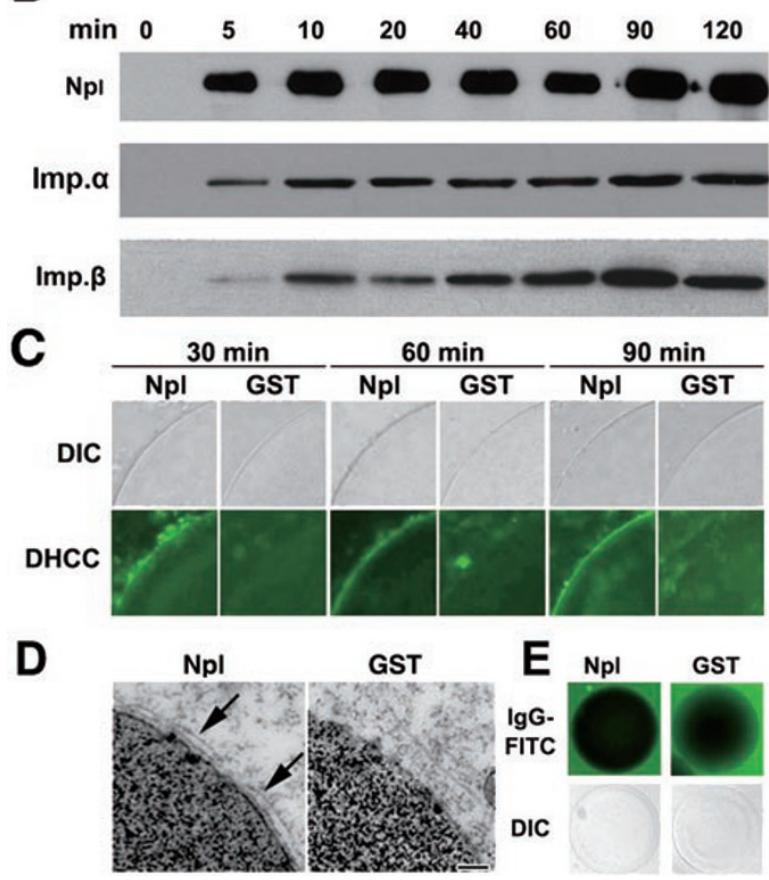

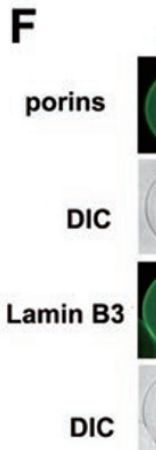
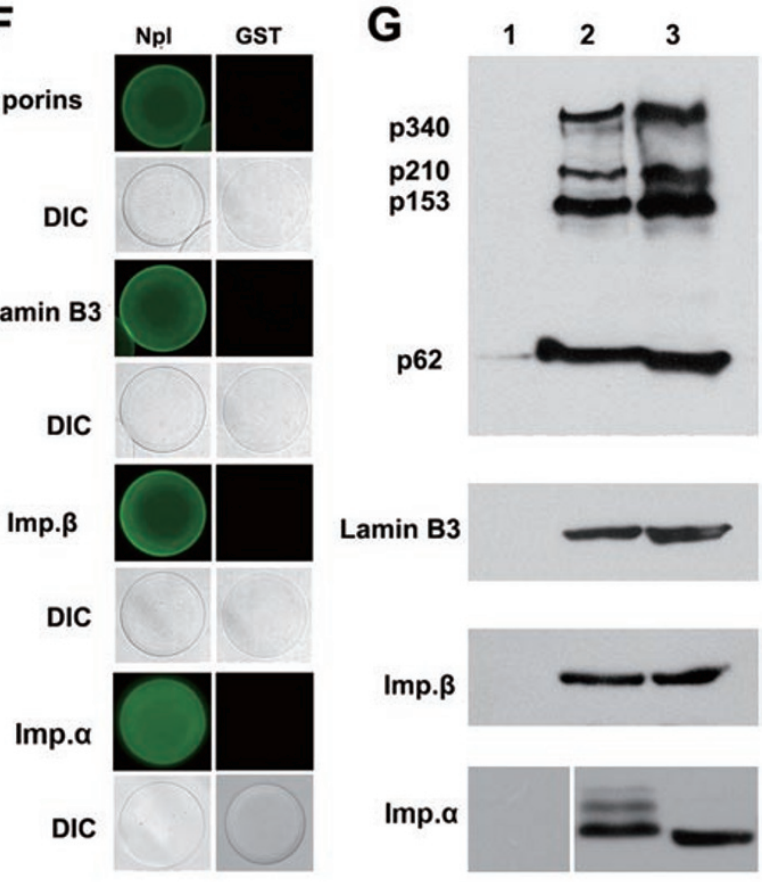

Lamin B3
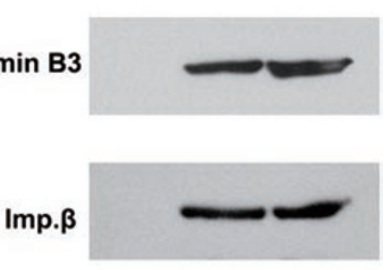

Imp.o
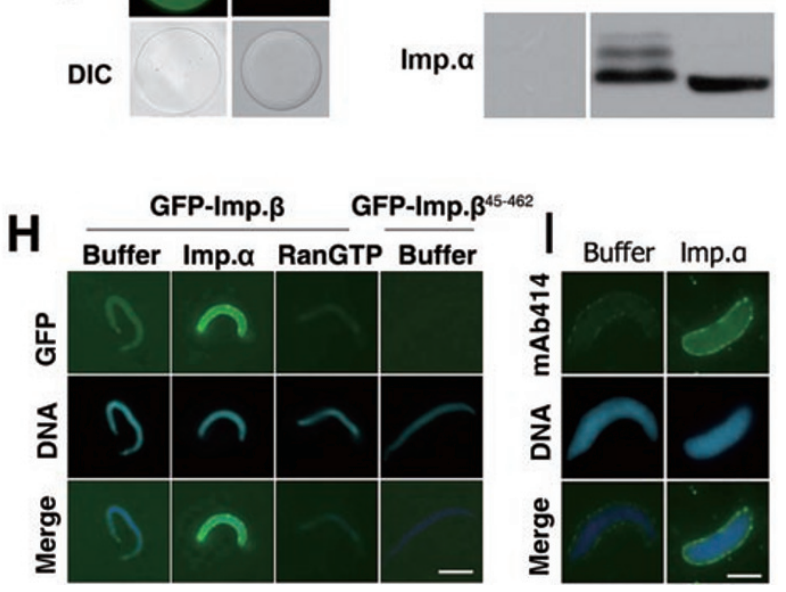

Figure 1 Nucleoplasmin induces NE assembly in Xenopus egg extracts. (A, B) Nucleoplasmin (Npl), importin- $\alpha$ (imp. $\alpha$ ) and importin- $\beta$ (Imp. $\beta$ ) bind to sperm chromatin rapidly in HSS viewed by immunofluorescence microscopy (A) and western blotting using anti nucleoplasmin, importin- $\alpha$ and importin- $\beta$ antibodies (B). Xenopus sperm chromatin was incubated in the extracts till to the time as indicated. DNA was counter-stained with the fluorescent dye DAPI. Scale bar, $5 \mu \mathrm{m}$. (C, D) Bacterially-expressed GST-fused nucleoplasmin and GST were bound to Glutathione-Sepharose and Dyna beads, respectively, and incubated in LSS at $23^{\circ} \mathrm{C}$. Samples were removed and stained with the fluorescent lipophilic dye DHCC for immediate observation (C) and TEM (D). Double-layered NE with NPCs around Dyna beads is indicated by arrows. Scale bar, $200 \mathrm{~nm}$. (E) After incubation at $23^{\circ} \mathrm{C}$ for $2 \mathrm{~h}$, FITC-IgG was added and incubated for $1 \mathrm{~h}$ further. Nucleoplasmin-Sepharose beads excluded the FITC-IgG extensively, suggesting that the membrane around the beads provided an effective barrier for large proteins. (F, G) Samples of nucleoplasmin and GST beads incubated with the egg extracts were subjected to immunofluorescence microscopy (F) and western blotting (G) using the anti nucleoporins (mAb414), lamin B3, importin- $\beta$ and importin- $\alpha$ antibodies. In G, lane 1 is the GST beads; lane 2, the nucleoplasmin beads and lane 3, the LSS (1 $\mu$ I). (H) GFPfused importin- $\beta$ or importin- $\beta^{45-462}$ proteins were added into Xenopus egg extracts directly or with importin- $\alpha$ or Ran-GTP. The binding of importin- $\beta$ with the chromatin was analyzed by fluorescence microscopy. Scale bar, $5 \mu \mathrm{m}$. (I) Appropriate exogenous importin- $\alpha$ promotes the recruitment of nucleoporins during NE assembly. Exogenous recombinant importin- $\alpha$ was added into the extracts at final concentration of $2 \mu \mathrm{M}$ and incubated for 10 min on ice. Then, the sperm chromatin and energy system were added and incubated for $30 \mathrm{~min}$ at $23^{\circ} \mathrm{C}$ to induce the nuclear assembly. The assembled nuclei were stained by incubating with Alexa Fluor $₫ 488$-conjugated mAb414 antibody for additional 10 min followed by direct observation under a fluorescence microscope. Scale bar, $5 \mu \mathrm{m}$.

$\mathrm{NE}$ around the beads (Figure $1 \mathrm{~F}$ and $1 \mathrm{G}$ ). To confirm whether the recruitment of importin- $\beta$ to the chromatin was adapted by importin- $\alpha$, and whether this process was regulated by Ran, we incubated GFP-fused importin- $\beta$ 
or importin- $\beta^{45-462}$, which lacks the importin- $\alpha$ - and Ranbinding domain, with Xenopus egg extracts alone and together with importin- $\alpha$ or Ran-GTP (Figure 1H). We observed that GFP-importin- $\beta$ could only very weakly bind the chromatin and that the binding was strongly enhanced by importin- $\alpha$. In contrast, in the presence of Ran-GTP, the binding of GFP-importin- $\beta$ to the chromatin was almost totally inhibited. Importin- $\beta^{45-462}$ could not bind chromatin at all no matter of existence of importin- $\alpha$ or Ran-GTP (Figure 1H; the data with importin- $\alpha$ or RanGTP are not shown). Moreover, appropriate concentration (up to $2 \mu \mathrm{M}$ ) of exogenous importin- $\alpha$ also promoted the recruitment of nucleoporins to chromatin surface for NE and NPC assembly (Figure 1I). Taken together, we concluded that the chromatin-bound nucleoplasmin offers a docking site for importin- $\beta$-mediated membrane vesicles and nucleoporins adapted by importin- $\alpha$ during $\mathrm{NE}$ assembly and that this process is regulated by Ran.

The NLS domain of nucleoplasmin is the docking site for membrane vesicles and nucleoporins mediated by importin- $\beta$ in NE assembly in Xenopus egg extracts

To investigate the functional domains of nucleoplasmin in NE assembly, we constructed a series of truncated forms of nucleoplasmin (Figure 2A and 2B). We examined the binding activities of these proteins with immobilized pure DNA or with histone mixtures as has been reported previously [38-41]. Our results showed that although the truncate Npl- $\Delta \mathrm{C} 80$ (only containing coredomain) could bind histones, the poly-E domain-containing truncated forms of nucleoplasmin had the strongest binding activity with histones, while none of the mutant proteins specifically bound pure DNA (Figure 2C). In a parallel experiment, we immobilized recombinant nucleoplasmin or the mutant protein onto the beads and incubated them with histones mixture. The results further showed that only poly-E-containing nucleoplasmin truncates could strongly bind $\mathrm{H}_{2} \mathrm{~A}$ and $\mathrm{H}_{2} \mathrm{~B}$, while Npl- $\Delta \mathrm{C} 80$ clearly had less binding affinity with the histones (Figure 2D). These findings demonstrate that nucleoplasmin binds to chromatin mainly through the interaction of its poly-E domain with histones $\mathrm{H}_{2} \mathrm{~A}$ and $\mathrm{H}_{2} \mathrm{~B}$.

Next we examined which domains of nucleoplasmin serve as docking sites for the targeting of the membrane vesicles and nucleoporins mediated by importin- $\beta$ during NE assembly. We coated the nucleoplasmin truncate proteins onto beads and incubated them with the egg extracts to monitor induction of NE assembly. Full-length nucleoplasmin and its NLS-containing truncates NplC50, Npl-C80 and Npl-NLS induced lipid accumulation around the beads (Figure 2E and 2F). By TEM, FEISEM (field emission in lens scanning electron microscopy), immunofluorescence labeling and western blotting, we confirmed that these lipid accumulations were doublelayered NE with NPCs over a nuclear lamina (Figure 3A and $3 \mathrm{~B}$ ). We compared endogenous nucleoplasmin from Xenopus egg extracts with bacteria-expressed nucleoplasmin in inducing NE assembly on beads and found no noticeable difference (Figure 2G1 and 2G2), suggesting that the recombinant proteins are fully functional. Interestingly, compared to the full-length nucleoplasmin protein, the NLS-containing truncate Npl-C50 or Npl-NLS alone could also induce NE and NPC assembly once incubated with the egg extracts (Figures 2E, 3A and 3B). In contrast, Npl- $\Delta \mathrm{C} 80$, which lacks the NLS domain, lost the ability of nucleoplasmin to recruit membranes and nucleoporins to induce NE and NPC assembly (Figures $2 \mathrm{E}, 3 \mathrm{~A}$ and $3 \mathrm{~B}$ ). To further confirm the role for nucleoplasmin in NE assembly, we depleted endogenous nucleoplasmin from the egg extracts and added DNA-coated Dyna beads to the extracts to induce NE assembly (Figure $2 \mathrm{H}-2 \mathrm{~J})$. The results showed that in mock-depleted extracts, nucleoplasmin could bind the DNA beads (Figure 2I) and induce lipid membrane accumulation around the beads (Figure 2J). In contrast, the DNA beads recruited none of nucleoplasmin in nucleoplasmin-depleted extracts and had almost no ability to gather the lipid membranes (Figure 2H-2J). Taken together, these data demonstrated that the NLS domain of nucleoplasmin is crucial for NE assembly.

Interaction of importin- $\beta$ with importin- $\alpha$ is required for NE assembly induced by nucleoplasmin in Xenopus egg extracts

To test the importance of importins in NE assembly, we performed immunostaining and determined that importin- $\beta$ could also function in NE and NPC assembly around beads coated with full-length nucleoplasmin or its NLS-containing truncates (Figure $3 \mathrm{~A}$ and $3 \mathrm{~B}$ ). We further depleted importin- $\beta$ from the egg extracts using RanQ69L (Figure 3C), a mutant defective in GTPase activity and therefore locked in the GTP-bound form, as previously described [22]. This depletion procedure removed almost all importin- $\beta$ but importin- $\alpha$ remained (Figure 3C). When extracts depleted of Ran-GTP-binding proteins $(\triangle \mathrm{RanBP})$ were incubated with Npl-beads, we found that the $\triangle$ RanBP extracts were deficient in the recruitment of membrane vesicles and nucleoporins to form the NE (Figure 3D). This defect was restored by adding $5 \mu \mathrm{M}$ importin- $\beta$ but not importin- $\beta^{45-462}$ to the $\triangle$ RanBP extracts (Figure $3 \mathrm{D}-3 \mathrm{~F}$ ). These results indicated that importin- $\beta$ has an essential role in the recruitment of membrane vesicles and nucleoporins for NE assembly initiated by nucleoplasmin and that the remain- 


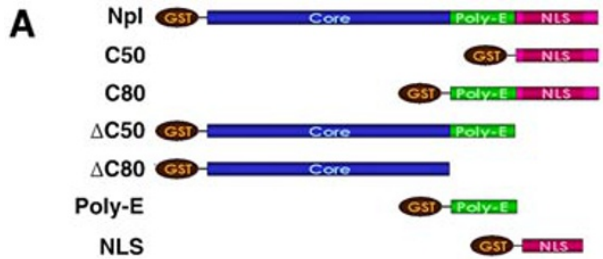

C
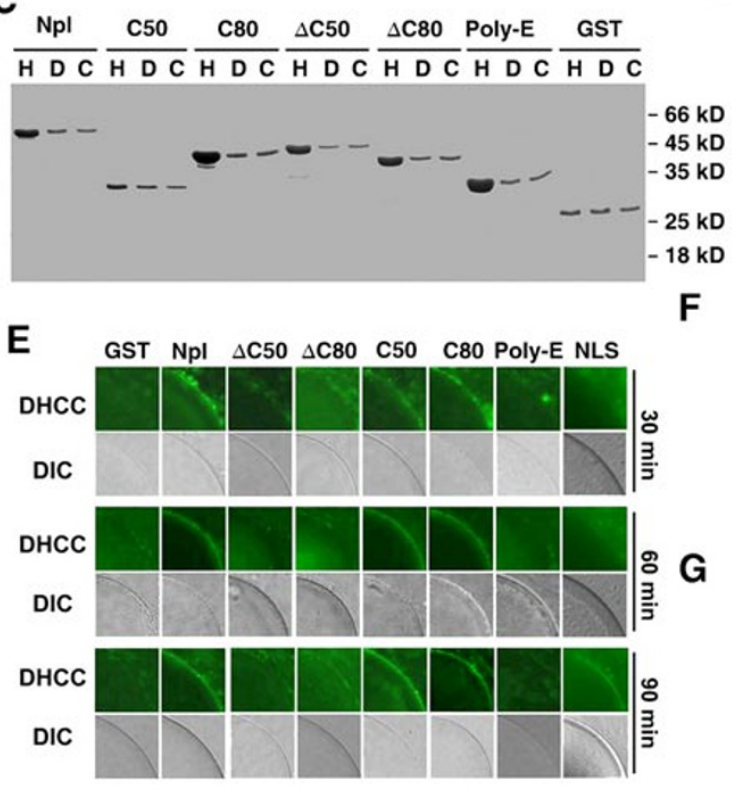

B GST Npl C50 C80 $\Delta$ C50 $\Delta$ C80 Poly-E

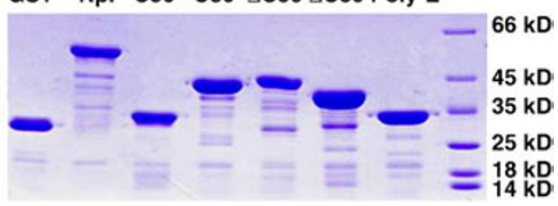

D

GST Npl C50 C80 $\Delta$ C50 $\Delta$ C80 Poly-E Histones
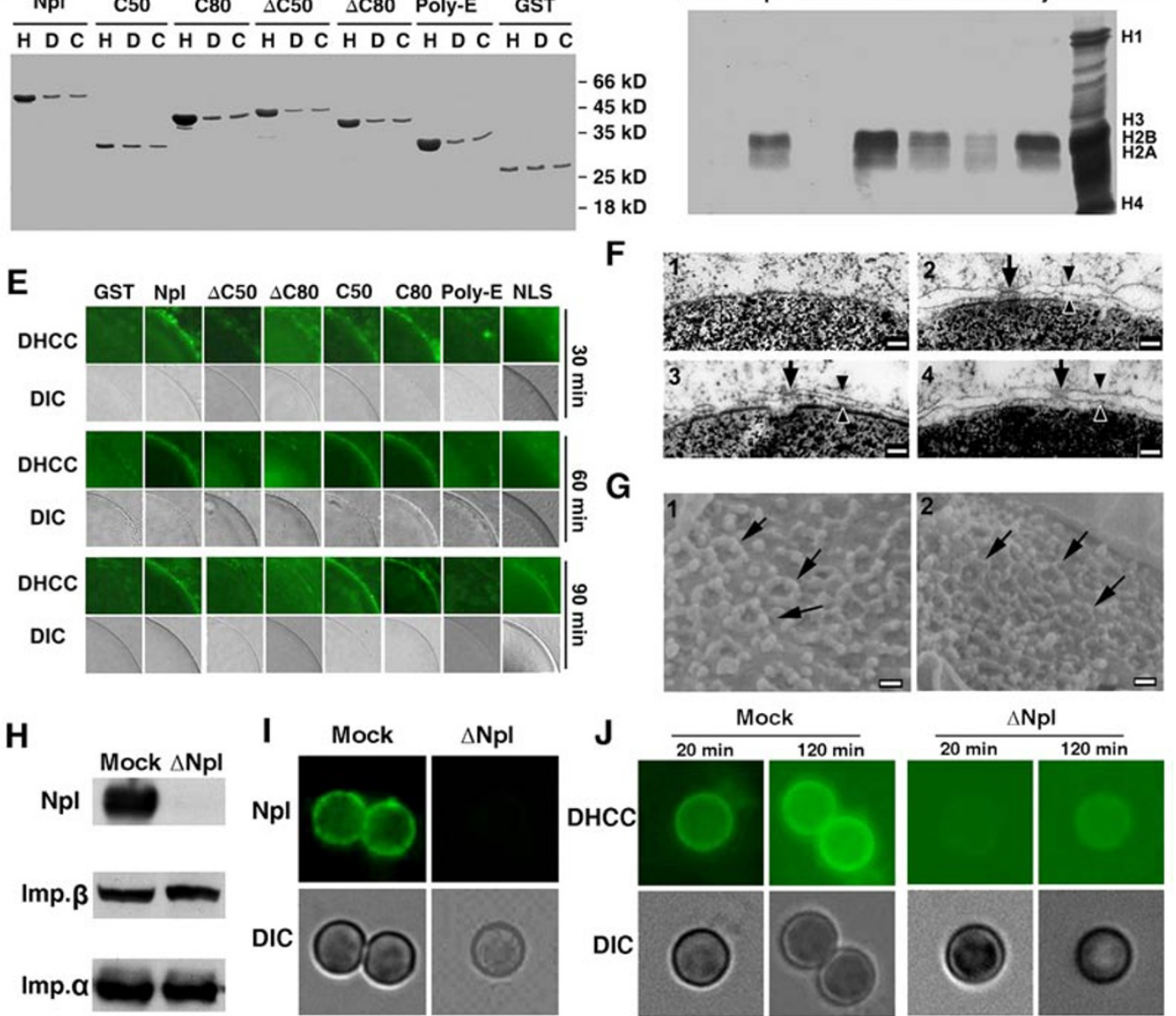

Figure 2 NLS domain-containing nucleoplasmin truncates are sufficient to induce NE assembly in Xenopus egg extracts. (A) Cartoon depicting the structure of nucleoplasmin and truncated mutants. (B) Purified bacteria-expressed GST-fused nucleoplasmin and nucleoplasmin truncates were separated in a 6\%-15\% SDS-PAGE gel. (C) Purified DNA or histone mixture was covalently loaded to $\mathrm{CNBr}$-activated Sepharose beads, and the beads were incubated with $5 \mu \mathrm{M}$ final concentration of nucleoplasmin or nucleoplasmin truncates for $20 \mathrm{~min}$ in KHM buffer. After washing for four times, the proteins on the beads were separated in a 4\%-15\% SDS-PAGE gel. The results showed that only poly-E domain-containing nucleoplasmin bound with Histones, but not DNA. H, histone mixture beads; D, DNA beads; C, control beads. (D) Purified nucleoplasmin or nucleoplasmin truncates were covalently loaded to CNBr-activated Sepharose beads, and the beads were incubated with $0.1 \mathrm{mg} / \mathrm{ml}$ final concentration of histone mixture for $20 \mathrm{~min}$ in KHM buffer. After washing for 4 times, proteins on the Sepharose beads were separated in a $12 \%$ SDS-PAGE gel. The poly-E domain of nucleoplasmin bound with histones $\mathrm{H}_{2} \mathrm{~A}$ and $\mathrm{H}_{2} \mathrm{~B}$ specifically. (E) Sepharose beads were loaded with nucleoplasmin or the truncated mutants and incubated in the LSS at $23^{\circ} \mathrm{C}$. Samples were stained with DHCC without fixation and examined immediately. (F) Dyna beads were loaded with GST as a negative control (1), the GST-fused nucleoplasmin (2) and the GST-fused truncates Npl-C50 (3) and Npl-C80 (4), and incubated in the egg extracts at $23{ }^{\circ} \mathrm{C}$ for $2 \mathrm{~h}$. Samples were prepared for TEM. The double-layered NE and the NPCs are indicated by arrowheads and arrows, respectively. Scale bar, $100 \mathrm{~nm}$. (G) Dynal beads were coated with full-length bacteria-expressed nucleoplasmin (1) and endogenous nucleoplasmin purified from Xenopus egg extracts (2) and incubated with LSS to induce NE assembly. The beads were viewed by FEISEM. Arrows indicate the NPCs. Scale bar, $100 \mathrm{~nm}$. (H) Immunodepletion of endogenous nucleoplasmin $(\Delta \mathrm{Npl}$ ) in Xenopus egg extracts using Npl antibody-coated beads. Almost all Npl was removed from the extract, while importin- $\alpha$ and importin- $\beta$ were not affected by Npl depletion. (I) Immunofluorescence microscopy showed that DNA beads could bind nucleoplasmin in mock- but not Npl-depleted extracts. (J) DNA beads could efficiently induce NE assembly in mockbut not in Npl-depleted egg extracts. The NE was stained with DHCC dye, and the beads were viewed by DIC. 
A

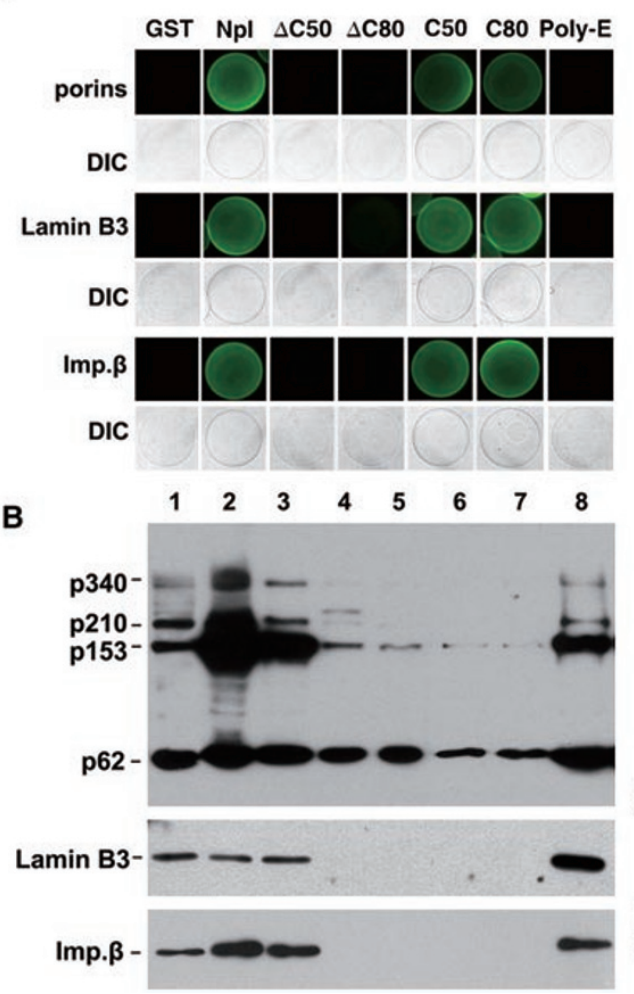

C

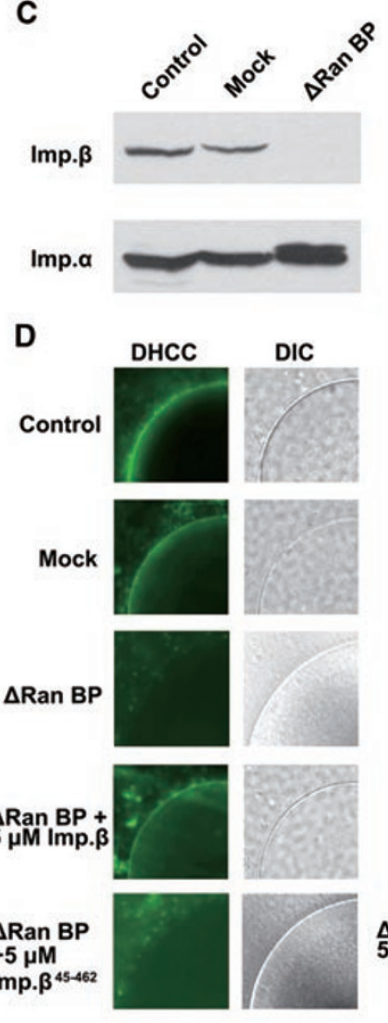

E

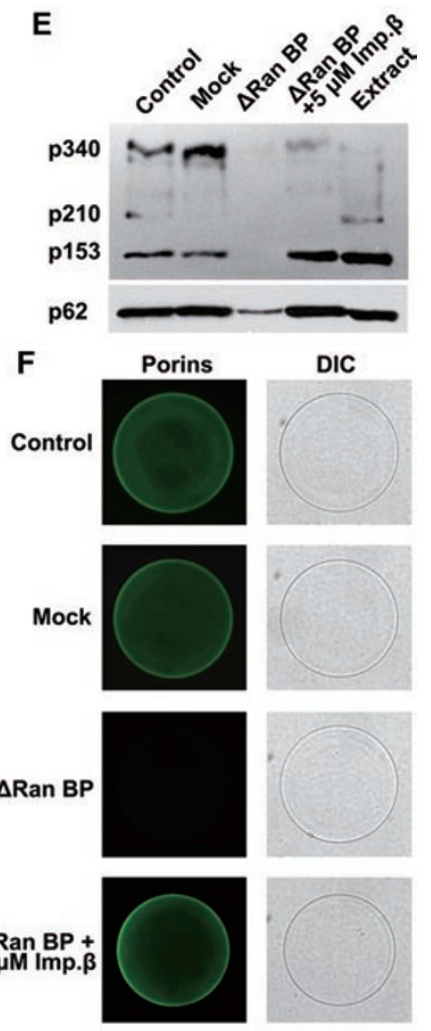

Figure 3 Importin- $\beta$ is required for NE assembly induced by nucleoplasmin beads. (A, B) Samples of Sepharose beads coated with GST or nucleoplasmin proteins were incubated in the LSS at $23^{\circ} \mathrm{C}$ for $2 \mathrm{~h}$ and subjected to immunofluorescence microscopy (A) and western blotting using the antibodies against nucleoporins (mAb414), lamin B3 and importin- $\beta$ (B). In B, (1) full-length GST-nucleoplasmin beads, (2) GST-Npl-C50 beads, (3) GST-Npl-C80 beads, (4) GST-Npl- $\triangle$ C50 beads, (5) GST $\mathrm{Npl}-\Delta \mathrm{C} 80$ beads, (6) GST-poly-E beads, (7) GST beads, and (8) LSS (1 $\mu$ l). (C) Depletion of importin- $\beta$ from Xenopus egg extracts using GST-RanQ69L Sepharose beads. Equal quantities of non-depleted (control), mock depleted with GST, or depleted with GST-RanQ69L ( $\triangle$ RanBP) extracts were analyzed by western blotting with anti importin- $\beta$, or importin- $\alpha$ antibodies. (D) NE assembly around the Sepharose beads coated with nucleoplasmin in Xenopus egg extracts either non-depleted (control), mock depleted with GST, or depleted with GST-RanQ69L ( $\triangle$ RanBP). Importin- $\beta$ or its truncate importin- $\beta^{45-462}$ was added to the extracts at a final concentration of $5 \mu \mathrm{M}$. After incubation for $90 \mathrm{~min}$, the beads were stained with DHCC for immediate examination. (E, F) Sepharose beads coated with nucleoplasmin were incubated in the egg extracts either non-depleted, mock depleted with GST, depleted with GST-RanQ69L ( $\triangle$ RanBP), or re-supplemented with importin- $\beta$ to a final concentration of $5 \mu \mathrm{M}$ before being incubated at $23^{\circ} \mathrm{C}$ for $2 \mathrm{~h}$ and analyzed by western blotting (E) or immunofluorescence microscopy using antibodies against nucleoporins (mAb414) (F).

ing importin- $\alpha$ alone was not sufficient to mediate this process. These data strongly suggest that importin- $\beta$ functions via combining with importin- $\alpha$ to recruit membrane vesicles and nucleoporins to the nucleoplasmin beads during NE assembly. We attempted to test the role of importin- $\alpha$ in this process by depleting this protein from extracts but were unsuccessful in removing all of this protein from the egg extracts. Nevertheless, we still believe our findings demonstrating that importin- $\alpha$ adapted between the chromatin-bound nucleoplasmin and importin- $\beta$-associated membrane vesicles and nucleoporins during NE assembly. Importin- $\alpha$ is expected to bind the chromatin-bound nucleoplasmin but not di- merize with importin- $\beta$ first, as depletion of importin- $\beta$ did not remove importin- $\alpha$ and importin- $\alpha$ alone could bind nucleoplasmin directly.

Interfering with the binding of importin- $\alpha$ and chromatinbound nucleoplasmin by excess soluble Npl-C50 blocks NE assembly

To further investigate the initiation of NE assembly by nucleoplasmin, we added a large excess of the truncated nucleoplasmin proteins Npl-C50, Npl- $\Delta$ C50 or NPL$\triangle \mathrm{C} 80$ to egg extracts to determine their effects on NE assembly around the sperm chromatin. Npl-C50, but not Npl- $\Delta$ C80 blocked NE assembly (Figure 4). Npl-C50 


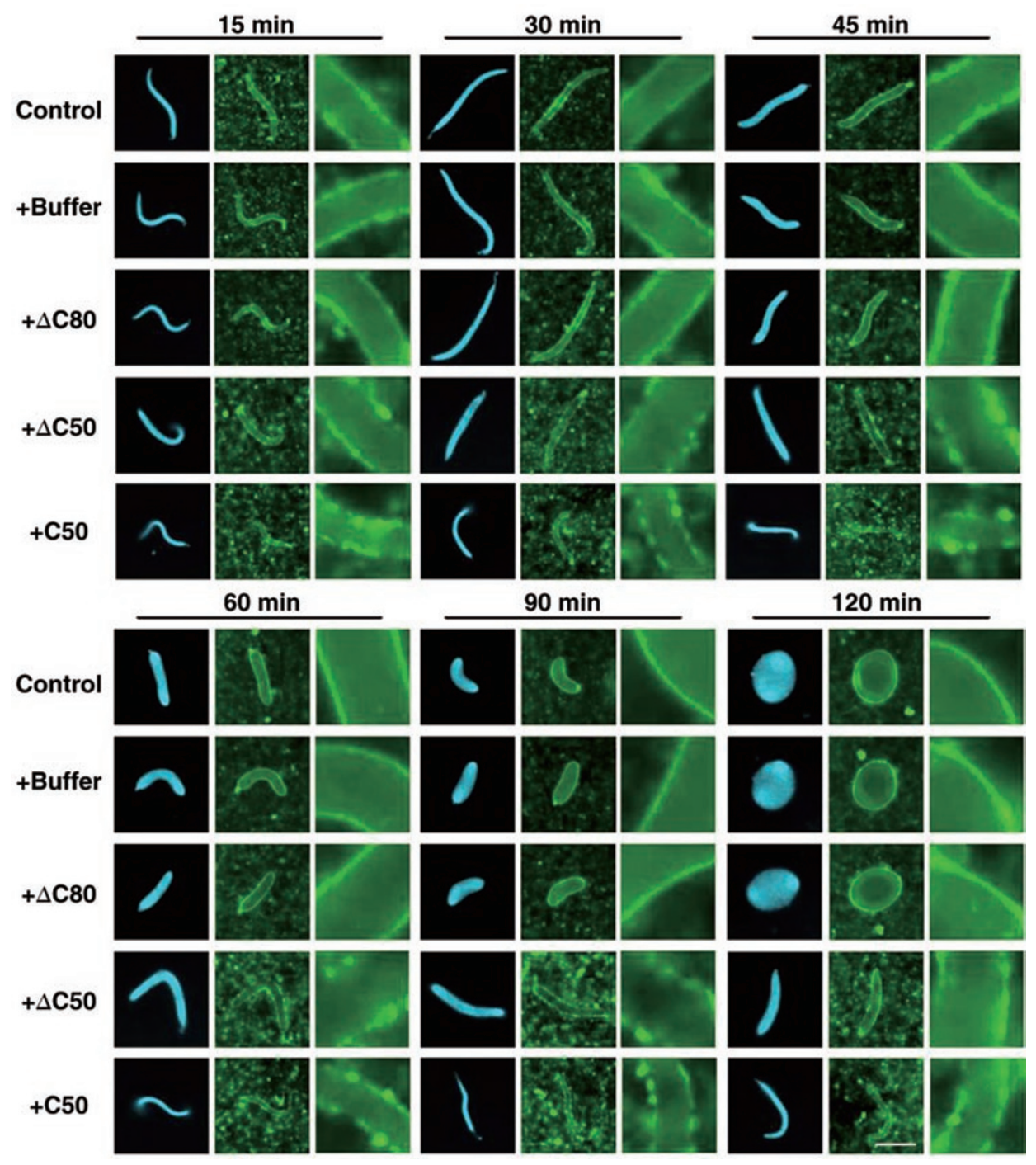

Figure 4 Blockage of the interaction of importin- $\alpha$ with sperm chromatin by NLS-containing Npl-C50 and poly-E-containing $\mathrm{Npl}-\Delta \mathrm{C} 50$ inhibits NE assembly around the chromatin in Xenopus egg extracts. GST-fused Npl- $\Delta$ C80, Npl- $\Delta$ C50 or Npl-C50 was added into the egg extracts to a final concentration of $20 \mu \mathrm{M}$. After incubation of the mixtures at $23^{\circ} \mathrm{C}$, samples were removed at the indicated times and stained with DHCC for membrane and DAPI for DNA for immediate observation. Buffer was used as a parallel normal control. Npl-C50, which has the NLS sequence and could compete with the endogenous nucleoplasmin for importin- $\alpha$, significantly inhibited NE assembly; while Npl- $\Delta$ C50, which has the poly-E domain and could compete with the endogenous nucleoplasmin for chromatin but no NLS for binding importin- $\alpha$, also inhibited NE assembly. By contrast, $\mathrm{Npl}-\Delta \mathrm{C} 80$ had no effects on NE assembly as it has neither the poly-E domain to compete with the endogenous nucleoplasmin for chromatin nor NLS domain to compete with NLS proteins on chromatin for importin- $\alpha$. The third columns of each panel were zoomed in from the second columns. Scale bar, $5 \mu \mathrm{m}$.

may block the interaction of chromatin-bound nucleoplasmin and importin- $\alpha$ as it can only bind importin- $\alpha$ but not chromatin, thus depleting the pool of available importin- $\alpha$. Npl- $\Delta$ C 50 , which can bind chromatin but not importin- $\alpha$, also blocked NE assembly. Npl- $\Delta$ C50 might compete with endogenous nucleoplasmin for chromatin through its poly-E domain, however we determined that this mutant was unable to recruit importin- $\alpha$ to the chromatin as short of an NLS domain. Npl- $\Delta \mathrm{C} 80$ did not affect NE assembly as it could not bind importin- $\alpha$ and only very weakly bind chromatin. Taken together, these data demonstrated that the chromatin-bound nucleoplasmin is crucial for recruiting membrane vesicles and nucleoporins via importin- $\alpha$ and $-\beta$ during NE assembly.

In addition to nucleoplasmin, histones and possibly NuMA are rich in Xenopus egg extracts, and thus may 
also be early-binding proteins to chromatin during NE assembly. To test whether other chromatin-bound NLS proteins contribute to NE assembly, we fused the NuMA C-terminal tail containing the NLS domain to GFP and expressed it in HeLa cells to test the effects on the cell cycle. We observed that, similar to the wild-type NuMA, NuMA tail was localized to the nucleus in interphase and relocalized to the mitotic spindle in mitosis (Figure $5 \mathrm{~A}$ ). Because the NuMA tail localized appropriately in HeLa cells, we tested recombinant GST-fused NuMA tail protein in NE assembly with Xenopus egg extracts. Like nucleoplasmin, the NuMA tail protein induced lipid accumulations (Figure 5B) containing importins, nucleoporins and lamin B3 (Data not shown). We also coated purified histones onto Sepharose beads and found that these beads were sufficient to induce the lipid accumulations (Figure 5C). Together these results indicate that NLS proteins bound to the chromatin contribute to NE assembly by providing their NLSs as docking sites for membrane vesicles and nucleoporins via importin- $\alpha$ and $-\beta$. However, the association of these protein with chro- matin are not equal, and therefore, their contributions to $\mathrm{NE}$ assembly must be varied. Thus we propose that abundant early chromatin-bound NLS proteins like nucleoplasmin, histones and NuMA largely contribute to NE assembly by providing their NLS domains for importin- $\alpha$. As nucleoplasmin is the most abundant NLS protein in Xenopus egg extracts that interacts with chromatin prior to histones [30], it might be particularly important for the initiation of NE assembly.

The membrane vesicles mediated by importin- $\beta$ for $N E$ assembly are not importin- $\alpha$-bound membranes

It has been reported that a fraction of importin- $\alpha$ but not importin- $\beta$ is present on the membrane vesicles and these importin- $\alpha$-bound vesicles have a role in NE assembly [25]. In this work, we also found that importin$\alpha$-bound membrane vesicles were present in the extract (Figure 6A). To test the importance of importin- $\alpha$ in directly targeting membrane vesicles to the chromatinbound NLS proteins, we depleted the importin- $\alpha$-bound membrane fraction ( $\Delta$ imp $\alpha$-membrane) from the total

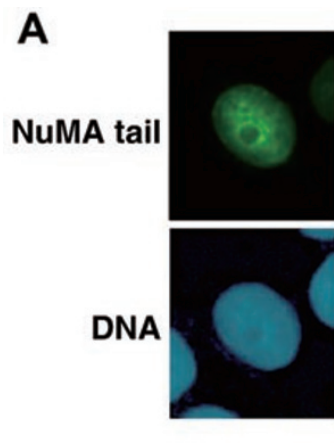

B

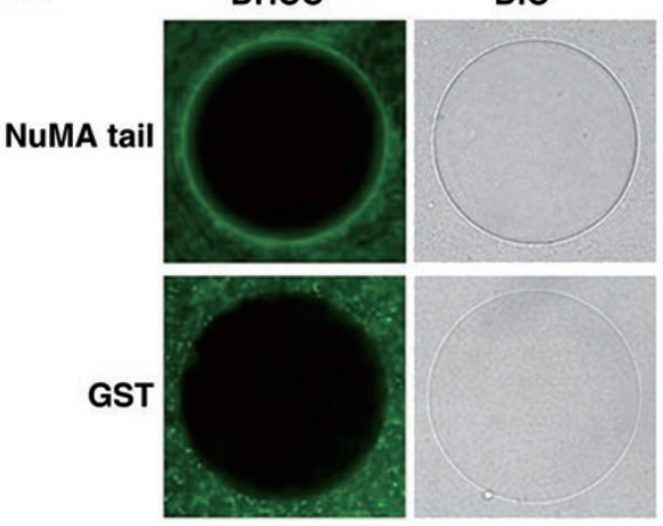

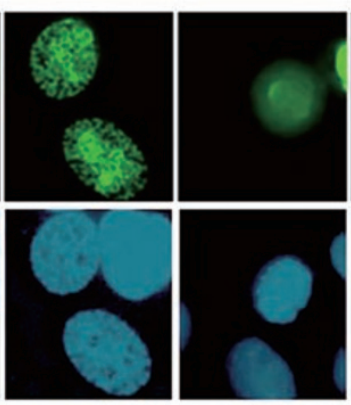
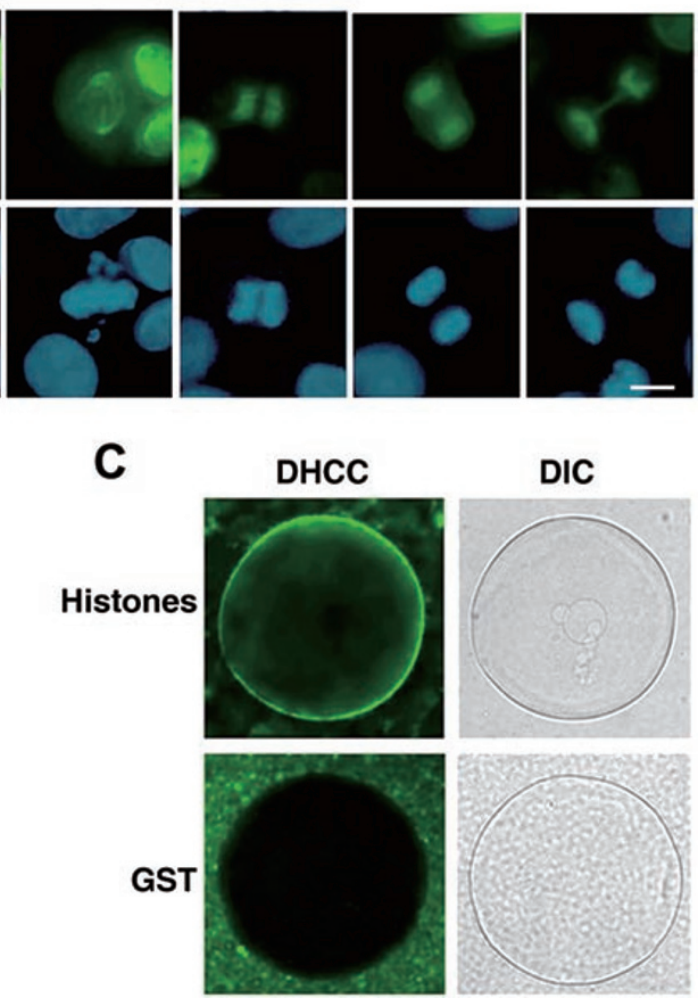

Figure 5 The NLS-containing NuMA tail and histones could induce NE assembly in Xenopus eggs extracts. (A) HeLa cells were transfected with GFP-NuMA tail and fixed after $24 \mathrm{~h}$. Scale bar, $10 \mu \mathrm{m}$. (B) Sepharose beads were loaded with GSTfused NuMA tail and incubated with LSS at $23{ }^{\circ} \mathrm{C}$ for $90 \mathrm{~min}$. Samples were stained with DHCC. (C) Histone mixture was immobilized onto CNBr-activated Sepharose beads and incubated with LSS at $23^{\circ} \mathrm{C}$ for 90 min. Samples were stained with DHCC. 


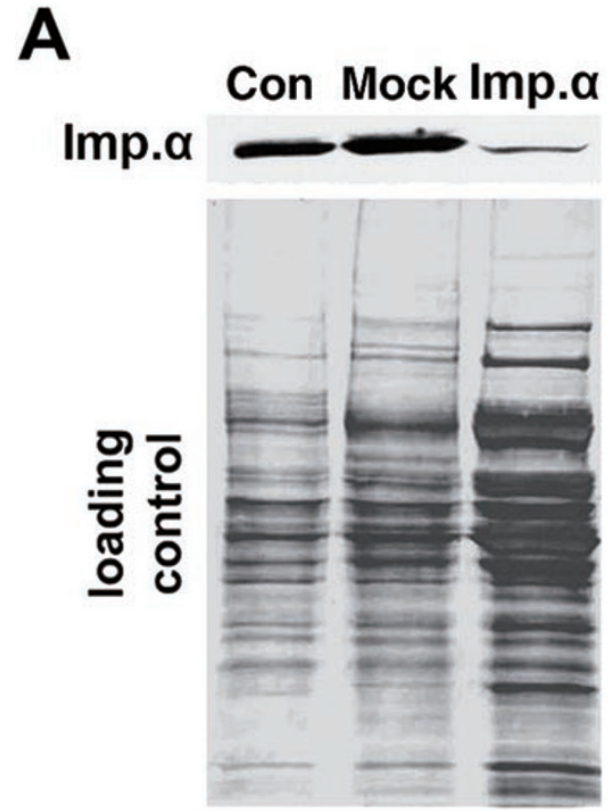

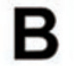

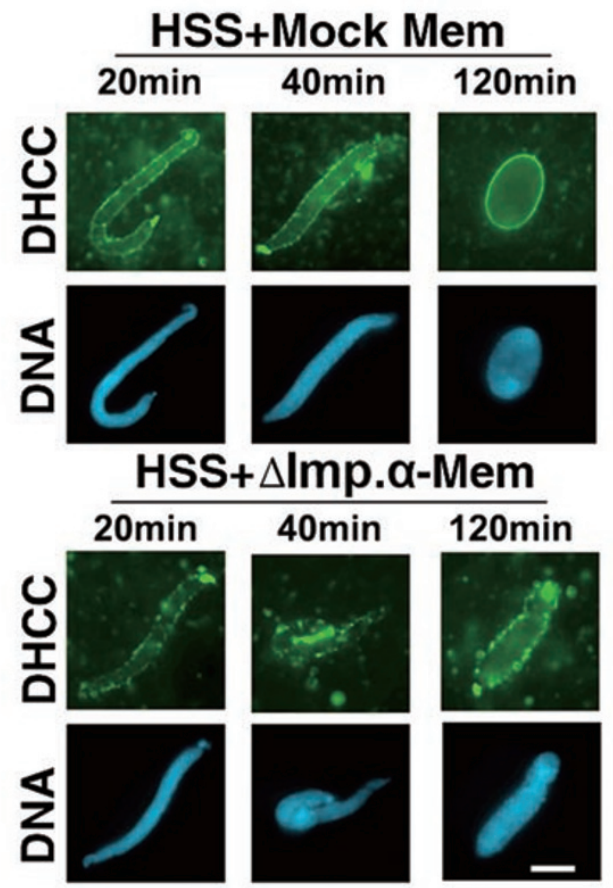

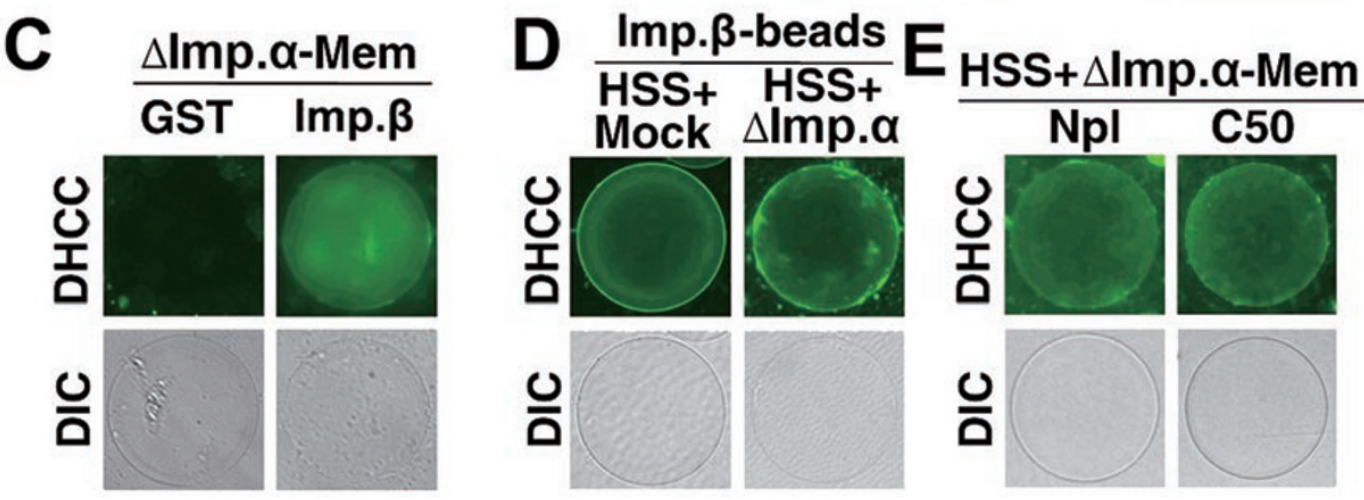

Figure 6 The membrane vesicles mediated by importin- $\beta$ for NE assembly are not importin- $\alpha$-bound membranes during NE assembly in Xenopus egg extracts. (A) Immunodepletion of importin- $\alpha$-bound membrane and western blotting analysis using anti importin- $\alpha$ antibody to check the depletion efficiency. $1 \mu \mathrm{l}$ per lane of regular membrane (related to total membranes from $10 \mu \mathrm{l}$ extracts) as control, mock-depleted membrane and importin- $\alpha$-depleted ( $\Delta \mathrm{imp} \alpha)$ membrane were analyzed by western blotting using an anti importin- $\alpha$ antibody. The Coomassie Blue staining was used as a loading control. (B) DHCC-prestained $\Delta$ imp $\alpha$ or mock-depleted membrane was added with demembranated sperm chromatin into the HSS and incubated at $23^{\circ} \mathrm{C}$. Samples were taken at the indicated times for immediate fluorescence observation. (C) DHCC-prestained $\Delta$ imp $\alpha$ or mockdepleted membrane was added with importin- $\beta$ Sepharose beads into PBS buffer and incubated for 30 min or into HSS and incubated for $5 \mathrm{~min}$ at $23^{\circ} \mathrm{C}$. (D) Importin- $\beta$ Sepharose beads incubated in HSS plus DHCC-prestained mock-depleted or $\Delta \mathrm{Imp} \alpha$ membrane for $5 \mathrm{~min}$ at $23^{\circ} \mathrm{C}$. Samples were taken for immediate fluorescence observation. (E) Full-length nucleoplasmin ( $\mathrm{Npl}$ ) or truncated $\mathrm{Npl-C50}$ Sepharose beads were added into HSS plus DHCC-prestained $\Delta$ imp $\alpha$ membrane or mockdepleted membrane (data not shown) and incubated for $5 \mathrm{~min}$ at $23^{\circ} \mathrm{C}$. Samples were taken for immediate fluorescence observation.

membranes (Figure 6A). As described previously, this procedure removed $\sim 90 \%$ of importin- $\alpha$-bound membranes [25]. We incubated sperm chromatin and $\Delta$ imp $\alpha-$ membrane in HSS and found that this $\Delta$ imp $\alpha$-membrane could still bind the chromatin, although the fusion of the vesicles was less efficient (Figure 6B). As importin- $\beta$ beads can directly bind the membrane vesicles and nucleoporins during NE assembly [22], we incubated importin- $\beta$ beads with the $\Delta$ imp $\alpha$-membrane or mockdepleted membrane in the HSS. We first tested whether 
the membranes could bind the importin- $\beta$ beads directly in buffer and observed that $\Delta$ imp $\alpha$-membrane could only weakly bind to the beads (Figure 6C). When incubated in the HSS, we found that both the $\Delta$ impo-membrane and the mock-depleted membrane could strongly bind importin- $\beta$ beads, although it seemed that the $\Delta$ imp $\alpha$ membrane vesicles had difficulties in fusing. This result suggested that importin- $\alpha$-bound membrane might be required for NE assembly by regulating membrane vesicle fusion (Figure 6D). Next, we incubated Npl or Npl-C50 beads with the $\Delta$ imp $\alpha$-membrane or the mock-depleted membrane in the HSS. Both $\Delta$ imp $\alpha$-membrane and mock-depleted membrane could bind $\mathrm{Npl}$ or Npl-C50 beads, although the binding to these beads was not as rapid as to importin- $\beta$ beads, suggesting that additional regulators were needed, which could be importin- $\alpha$ and importin- $\beta$ (Figure 6D and 6E). Thus we conclude that the targeting of the membrane vesicles and nucleoporins to the chromatin-bound NLS proteins via importin- $\alpha$ and $-\beta$ may be the main mechanism for the initiation of NE assembly. However, we cannot exclude the possibility that a small fraction of the membrane vesicles could be targeted to the chromatin NLS proteins directly by importin- $\alpha$ through its direct binding to the vesicles and the NLS [25]. It will be important to identify importin- $\alpha$ domains that bind to vesicles. Our expectation is that different domains of importin- $\alpha$ binds the membrane vesicles while another targets the vesicles to the NLS sites on the chromatin.

\section{Discussion}

Our present study reveals a critical molecular mechanism that elucidates the initiation of NE assembly around the sperm chromatin in Xenopus egg extracts (Figure 7). When sperm chromatin is introduced into the egg ex-
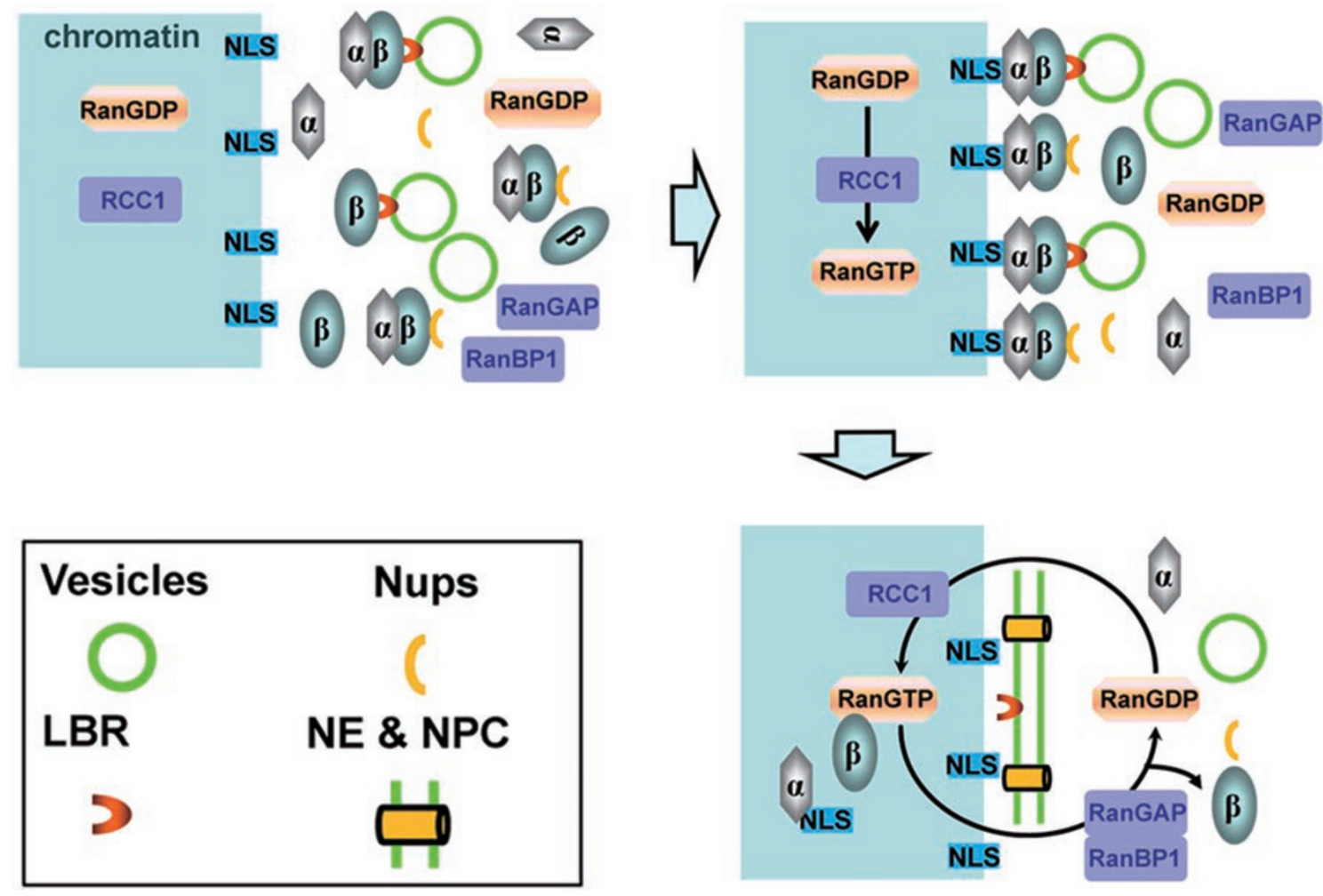

Figure $7 \mathrm{~A}$ simple model for the role of NLS proteins in recruiting membrane vesicles/nucleoporins for NE assembly in Xenopus egg extracts via importin- $\alpha$ and $-\beta$. At the end of mitosis, chromatin recruits NLS proteins promoted by Ran-GDP and RCC1, followed by importin- $\alpha$ binding to the NLS proteins on the chromatin. Simultaneously, importin- $\beta$ binds with nucleoporins or membrane vesicles. Through interaction of the NLS protein-bound importin- $\alpha$ with the nucleoporin- or membrane vesicle-bound importin- $\beta$, the nucleoporins and membrane vesicles are recruited to the surface of the chromatin. Once encountering Ran-GTP generated from Ran-GDP by RCC1 on chromatin, importin- $\beta$ selectively binds Ran-GTP and releases nucleoporins, membrane vesicles and importin- $\alpha$ with NLS proteins. Then the membrane vesicles fuse to form the double-layered NE and the nucleoporins assemble into the NPCs under the regulation of Ran through hydrolyzing its GTP molecule stimulated by RanGAP and RanBP1. Once separated, importin- $\beta$ and Ran in GDP-bound form start the next cycle of the above process. 
tracts, the abundant NLS proteins nucleoplasmin and histones are rapidly recruited onto the chromatin, followed by the binding of importin- $\alpha$ to the NLS proteins on the chromatin. During this process importin- $\beta$ in the extracts binds the membrane vesicles [28] and nucleoporins [22] in the cytoplasm. Through dimerization with importin- $\alpha$ on the chromatin NLS proteins, importin- $\beta$ targets bound membrane vesicles and nucleoporins to the surface of the chromatin. Once encountering with Ran in its GTPbound form, generated by RCC1 on the chromatin, the membrane vesicles- or nucleoporins-bound importin- $\beta$ will preferentially bind Ran-GTP, resulting in the release of free vesicles and nucleoporins around the chromatin for NE and NPC assembly.

This working model could comprehensively elucidate the metaphase to anaphase transition regulated by cell cycle regulators and Ran GTPase system. During early mitosis, Ran is dispersed in the cytoplasm during chromatin condensation into chromosomes and the NE disassembly, while RCC1 stays bound to the chromosomes. In the Ran-GTP gradient theory [23], high concentrations of Ran-GTP around the RCC1-bound chromosomes in metaphase should prevent the binding of importin- $\beta$ with importin- $\alpha$ by preferentially binding with importin- $\beta$, resulting in the combination of importin- $\alpha$ with the spindle assembly factors such as the NLS proteins TPX2 and NuMA. In experimental conditions for spindle assembly in M phase egg extracts, RanQ69L-GTP dissociates NLS proteins from endogenous importin- $\alpha$ or directly affects importin- $\beta$ by preferentially interacting with importin- $\beta$ and lifting its inhibitory effects on these proteins for spindle assembly $[42,43]$. During the metaphase to anaphase transition in Xenopus egg extracts, Ran and RCC1 bind to the chromatin $[14,44]$, generating an environment favorable for NE assembly, in which the NLS proteins should be allowed to bind the chromatin and importin- $\alpha$ bind to the NLS proteins. Meanwhile, importin- $\beta$ should be able to bind its cargoes around the chromatin since the Ran-GTP level is low. Therefore, confinement of Ran on chromatin should be a critical step in NE assembly. Although in an extreme condition without Ran (e.g., using heat-treated egg extracts in which nucleoplasmin is still active to decondense the sperm chromatin) nucleoplasmin could bind the sperm chromatin, the binding of nucleoplasmin to the chromatin in the egg extracts can be affected by adding Ran, suggesting that the binding of nucleoplasmin to the chromatin is physiologically regulated. Therefore, using a decondensed sperm chromatin in heat-treated egg extracts beforehand to induce NE assembly may not be a good way to study the initiation of $\mathrm{NE}$ assembly as it changes the physiological regulation steps of the recruitment of nucleoplasmin, Ran, RCC1, etc. to the chromatin. Therefore, we propose that the regulated binding of the NLS proteins to the chromatin by metaphase-anaphase transition regulators in Xenopus egg extracts may be one of the earliest steps for NE assembly, and importin- $\alpha$ serves as an adapter between the NLS proteins bound on the chromatin and importin- $\beta$.

In somatic cells, the initiation process of NE assembly must be more complicated although little is known about this process. However, it is still very likely through the similar mechanism to that in Xenopus egg extracts as the somatic cell chromosomes have abundant NLS proteins including histones. When the cell starts its NE assembly, the NLS proteins, such as NuMA and nucleoplasmin homologues, will also bind the daughter chromosomes except for the chromosome-bound NLS proteins. This somatic NE assembly initiation process must be more tightly regulated as the metaphase chromosome NLS proteins such as histones have been modified only suitable for the NE disassembly but not reassembly, and will not initiate the recruitment of importins, membrane vesicles and nucleoporins although they physically locate on the chromosomes. One regulation for this process might be post-translational modifications such as phosphorylation/dephosphorylation of those involved proteins during the metaphase-anaphase transition. The binding of importin- $\beta$ with its cargos is also regulated by phosphorylation/dephosphorylation during NE assembly in somatic cells as well as in Xenopus egg extract [29]. For more comprehensive understanding of NE assembly, much more work is still needed in the future.

\section{Materials and Methods}

\section{Molecular cloning, protein purification and antibody prepa- ration}

The coding region of nucleoplasmin was amplified from the total RNA of Xenopus XTC cells by RT-PCR and constructed into pGEX4T-1 (Pharmacia). Expressed GFP-nucleoplasmin and its truncates were purified using Glutathione Sepharose-4B (Pharmacia) according to the manual, desalted using a G-25 column and suspended in KHM buffer ( $78 \mathrm{mM} \mathrm{KCl}, 50 \mathrm{mM}$ HEPES, $\mathrm{pH} 7.0$, $4 \mathrm{mM} \mathrm{MgCl}_{2}, 2 \mathrm{mM}$ EGTA and $1 \mathrm{mM}$ DTT). Antibody against nucleoplasmin was prepared as described [32].

The coding regions of importin- $\alpha$ and $-\beta$ were amplified from Xenopus oocyte cDNA library and constructed into pET28a (Novagen). Expressed proteins were purified by TALON Medal Affinity Resin (BD Biosciences Clontech) according to the manual, desalted using a G-25 column and suspended in KHM buffer. Antibody against importin- $\alpha$ was raised by immunizing rabbits. Anti importin- $\beta$ antibody was purchased from Transduction Laboratories (MA3-070).

The GST-fused protein of Ran and its mutants RanQ69L and RanT24N were prepared as previously described [45]. Wild-type Ran and RanT24N were loaded with GDP, while RanQ69L was loaded with GTP. 
DNA fragment encoding the NuMA tail from amino acids 1 688 to 2102 was obtained by PCR from the template of plasmid containing full-length human NuMA cDNA (a kind gift from Dr TK Tang, Institute of Biomedical Sciences, Academia Sinica, Tai-

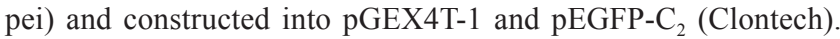
The GST-fused NuMA tail was prepared as above.

\section{Immobilization of proteins or DNA to the beads}

Glutathione Sepharose-4B beads were washed with PBS for four times, and mixed with purified GST-tagged nucleoplasmin or nucleoplasmin truncates at the final protein concentration of $5 \mu \mathrm{M}$. The mixture was incubated at room temperature for $1 \mathrm{~h}$. The beads were washed with PBS for three times and with KHM buffer for two times. Nucleoplasmin truncate proteins or DNA was coated onto Dyna beads according to the protocol (Invitrogen Dynal). Histones, NuMA tail and DNA were immobilized onto CNBractivated Sepharose 4B beads (Amersham Biosciences, Uppsala, Sweden) as the manual described, respectively. The beads were washed and finally suspended in KHM buffer.

Xenopus eggs extracts and demembranated Xenopus sperm chromatin preparation and NE assembly

Low-speed supernatant (LSS) and HSS (termed S-200) of egg extracts were prepared as described [46]. LSS, HSS S-200 and membranes were frozen and stored in aliquots in liquid nitrogen until use. Sperm were released from testes by gently squeezing the dissected testes in nuclear isolation buffer (NIB: $15 \mathrm{mM} \mathrm{NaCl}, 60$ $\mathrm{mM} \mathrm{KCl}, 15 \mathrm{mM}$ Tris-HCl, pH 7.5, 1 mM DTT, $0.5 \mathrm{mM}$ spermine, and $0.25 \mathrm{M}$ sucrose), centrifuged at $100 \times \mathrm{g}$ for $1 \mathrm{~min}$ at $4{ }^{\circ} \mathrm{C}$ to remove somatic tissue. Sperm-containing supernatant was centrifuged at $1500 \times \mathrm{g}$ for $10 \mathrm{~min}$ at $4{ }^{\circ} \mathrm{C}$. The pellet was re-suspended in NIB and incubated in the presence of $0.05 \%$ lysolecithin for $8-10 \mathrm{~min}$ at $22{ }^{\circ} \mathrm{C}$. The reaction was stopped by adding three volumes of cold NIB plus $3 \%$ bovine serum albumin. After washing three times with NIB, the demembranated sperm chromatin was stored in aliquots in liquid nitrogen at $10^{8} / \mathrm{ml}$.

\section{Preparation of nucleoplasmin-depleted egg extracts}

Nucleoplasmin depletion was carried out as described [36]. Briefly, LSS extracts was mixed with an equal volume of Protein A-Sepharose beads coated with nucleoplasmin antibody, incubated at $4{ }^{\circ} \mathrm{C}$ for $45 \mathrm{~min}$ and centrifuged. The supernatant was resubjected to this procedure twice to produce the nucleoplasmin proteins-depleted $(\Delta \mathrm{Npl})$ extracts. Mock-depleted extracts using Protein A-Sepharose beads coated with control rabbit IgG were prepared similarly.

\section{Importin- $\beta$ depletion from Xenopus egg extracts}

LSS was mixed with an equal volume of glutathione-Sepharose 4B beads coated with GST-RanQ69L loaded with GTP, incubated at $4{ }^{\circ} \mathrm{C}$ for $60 \mathrm{~min}$ and centrifuged. The supernatant was resubjected to this procedure twice to produce the $\triangle$ RanBP extracts. Mock-depleted extracts using Glutathione-Sepharose 4B beads coated with GST proteins were prepared in the same way.

\section{Preparation of importin- $\alpha$-depleted membranes}

The depletion was carried out as described [25]. Briefly, importin- $\alpha$-depleted extracts were generated by incubating with rabbit anti importin- $\alpha$ antibody-coated protein A Sepharose beads at $4{ }^{\circ} \mathrm{C}$ for $60 \mathrm{~min}$. And the beads were removed by centrifugation. Mock-depleted extracts using protein A Sepharose beads coated with control rabbit IgG were prepared in the same way. The importin- $\alpha$-depleted membranes were separated from the depleted extracts by ultra high speed centrifugation $(200000 \times g)$. After centrifugation, the membranes in the pellet were resuspended as $\Delta$ impa membranes and the supernatant was collected as importin$\alpha$-depleted ( $\Delta$ imp $\alpha)$ HSS extracts.

\section{NE assembly in Xenopus egg extracts}

LSS of Xenopus egg extracts was mixed with ATP-regenerating system and the demembranated sperm chromatin. A typical reaction contained $20 \mu \mathrm{l}$ of LSS, $1 \mu \mathrm{l}$ of ATP-regenerating system and $2000 \mu 1$ demembranated sperm chromatin final or $400 \mu \mathrm{l} \mathrm{Sep-}$ harose beads coated with proteins. The $20 \mu \mathrm{l}$ of LSS could be replaced with $18 \mu 1$ extracts S-200 and $2 \mu 1$ membranes. The mixture was incubated at $23{ }^{\circ} \mathrm{C}$ and shaken gently every $10 \mathrm{~min}$.

\section{Immunofluorescence labeling and western blotting analysis}

The samples were removed after incubation at $23{ }^{\circ} \mathrm{C}$ for a certain time, and diluted with $\mathrm{EB}$ buffer $(100 \mathrm{mM} \mathrm{KCl}, 20 \mathrm{mM}$ HEPES, pH 7.5, $5 \mathrm{mM} \mathrm{MgCl}$ and $2 \mathrm{mM} \beta$-mercaptoethanol). The nucleus or the beads were isolated by centrifugation at $1500 \times \mathrm{g}$ through a cushion of $30 \%$ glycerol in $1 / 3$ EB buffer. The samples were then lysed in SDS sample buffer for western blotting or fixed for immunofluorescence labeling.

\section{TEM and FEISEM}

For TEM, the samples were removed after incubation at $23{ }^{\circ} \mathrm{C}$ for the indicated time and fixed with glutaraldehyde in $0.1 \mathrm{M}$ sodium cacodylate buffer at final concentration of $2.5 \%(\mathrm{v} / \mathrm{v})$ at room temperature for $1 \mathrm{~h}$. The samples were rinsed and post-fixed with $1.5 \% \mathrm{OsO}_{4}$ in $0.1 \mathrm{M}$ sodium cacodylate buffer at room temperature for $1 \mathrm{~h}$. After dehydration in a graded series of ethanol and acetone (15 min each), the samples were embedded in the resin Spur and sectioned with a diamond knife and a Leica Ultracut R cutter. After staining with uranyl acetate and lead citrate, the sections were observed under a TEM JEM-1010 and images were captured with an AMT CCD camera.

For FEISEM, the fixed samples were dehydrated through a graded series of ethanol and transferred to Arklone for critical point drying using the highest purity $\mathrm{CO}_{2}$ in a Hitachi HCP-2 Critical Point Dryer. The samples were then coated with $4 \mathrm{~nm}$ Gold in a Hitachi E-1045 ION Sputter and viewed in a Hitachi scanning electron microscope $\mathrm{S} 4800$ at $6 \mathrm{kV}$ accelerating voltage.

\section{Cell transfection}

HeLa cells were grown on glass coverslips in Dulbecco's modified Eagle's medium with $10 \%$ fetal calf serum and transfected with pEGFP-C2-NuMA-tail using the standard calcium phosphate transfection protocol. After $24 \mathrm{~h}$, cells were fixed in methanol for 6 min at $-20^{\circ} \mathrm{C}$, stained with $4^{\prime} 6^{\prime}$-diamidino-2-phenylindole (DAPI) and observed with a fluorescence microscope.

\section{Acknowledgments}

We gratefully thank all the other members in our laboratories for helpful comments. We thank Dr TK Tang for providing the plasmid containing full-length NuMA cDNA. This work was 
supported by grants from the State Key Basic Research and Development Plan (2010CB833705) and the National Natural Science Foundation of China (30900726, 31071188, 31030044 and 90913021) to CZ, and by a Royal Society-Wolfson Research Merit Award to PRC.

\section{References}

1 Vasu SK, Forbes DJ. Nuclear pores and nuclear assembly. Curr Opin Cell Biol 2001; 13:363-375.

2 Mitchell JM, Mansfeld J, Capitanio J, Kutay U, Wozniak RW. Pom121 links two essential subcomplexes of the nuclear pore complex core to the membrane. J Cell Biol 2010; 191:505521.

3 Fichtman B, Ramos C, Rasala B, Harel A, Forbes DJ. Inner/ Outer nuclear membrane fusion in nuclear pore assembly: biochemical demonstration and molecular analysis. Mol Biol Cell 2010; 21:4197-4211.

4 Hetzer MW, Wente SR. Border control at the nucleus: biogenesis and organization of the nuclear membrane and pore complexes. Dev Cell 2009; 17:606-616.

5 Gant TM, Wilson KL. Nuclear assembly. Annu Rev Cell Dev Biol 1997; 13:669-695.

6 Rasala BA, Ramos C, Harel A, Forbes DJ. Capture of AT-rich chromatin by ELYS recruits POM121 and NDC1 to initiate nuclear pore assembly. Mol Biol Cell 2008; 19:3982-3996.

7 Gillespie PJ, Khoudoli GA, Stewart G, Swedlow JR, Blow JJ. ELYS/MEL-28 chromatin association coordinates nuclear pore complex assembly and replication licensing. Curr Biol 2007; 17:1657-1662.

8 Franz C, Walczak R, Yavuz S, et al. MEL-28/ELYS is required for the recruitment of nucleoporins to chromatin and postmitotic nuclear pore complex assembly. EMBO Rep 2007; 8:165-172.

9 Rasala BA, Orjalo AV, Shen Z, Briggs S, Forbes DJ. ELYS is a dual nucleoporin/kinetochore protein required for nuclear pore assembly and proper cell division. Proc Natl Acad Sci USA 2006; 103:17801-17806.

10 Walther TC, Askjaer P, Gentzel M, et al. RanGTP mediates nuclear pore complex assembly. Nature 2003; 424:689-694.

11 Walther TC, Alves A, Pickersgill H, et al. The conserved Nup107-160 complex is critical for nuclear pore complex assembly. Cell 2003; 113:195-206.

12 Fernandez AG, Piano F. MEL-28 is downstream of the Ran cycle and is required for nuclear-envelope function and chromatin maintenance. Curr Biol 2006; 16:1757-1763.

13 Antonin W, Franz C, Haselmann U, Antony C, Mattaj IW. The integral membrane nucleoporin pom 121 functionally links nuclear pore complex assembly and nuclear envelope formation. Mol Cell 2005; 17:83-92.

14 Zhang C, Goldberg MW, Moore WJ, Allen TD, Clarke PR. Concentration of Ran on chromatin induces decondensation, nuclear envelope formation and nuclear pore complex assembly. Eur J Cell Biol 2002; 81:623-633.

15 Hetzer M, Bilbao-Cortes D, Walther TC, Gruss OJ, Mattaj IW. GTP hydrolysis by Ran is required for nuclear envelope assembly. Mol Cell 2000; 5:1013-1024.

16 Ryan KJ, McCaffery JM, Wente SR. The Ran GTPase cycle is required for yeast nuclear pore complex assembly. J Cell Biol
2003; 160:1041-1053.

17 Zhang C, Clarke PR. Chromatin-independent nuclear envelope assembly induced by Ran GTPase in Xenopus egg extracts. Science 2000; 288:1429-1432.

18 Zhang C, Clarke PR. Roles of Ran-GTP and Ran-GDP in precursor vesicle recruitment and fusion during nuclear envelope assembly in a human cell-free system. Curr Biol 2001; 11:208-212.

19 Hutchins JR, Moore WJ, Clarke PR. Dynamic localisation of Ran GTPase during the cell cycle. BMC Cell Biol 2009; 10:66.

20 Liu Q, Yu J, Zhuo X, Jiang Q, Zhang C. Pericentrin contains five NESs and an NLS essential for its nucleocytoplasmic trafficking during the cell cycle. Cell Res 2010; 20:948-962.

21 Jiang Q, Lu Z, Zhang C. Role of Ran GTPase in cell cycle regulation. Chinese Sci Bull 2004; 49:535-541.

22 Zhang C, Hutchins JR, Muhlhausser P, Kutay U, Clarke PR. Role of importin-beta in the control of nuclear envelope assembly by Ran. Curr Biol 2002; 12:498-502.

23 Clarke PR, Zhang C. Spatial and temporal coordination of mitosis by Ran GTPase. Nat Rev Mol Cell Biol 2008; 9:464-477.

24 Harel A, Chan RC, Lachish-Zalait A, Zimmerman E, Elbaum $\mathrm{M}$, Forbes DJ. Importin beta negatively regulates nuclear membrane fusion and nuclear pore complex assembly. Mol Biol Cell 2003; 14:4387-4396.

25 Hachet V, Kocher T, Wilm M, Mattaj IW. Importin alpha associates with membranes and participates in nuclear envelope assembly in vitro. EMBO J 2004; 23:1526-1535.

26 Gorlich D, Vogel F, Mills AD, Hartmann E, Laskey RA. Distinct functions for the two importin subunits in nuclear protein import. Nature 1995; 377:246-248.

27 Clarke PR, Zhang C. Spatial and temporal control of nuclear envelope assembly by Ran GTPase. Symp Soc Exp Biol 2004; 56:193-204.

28 Ma Y, Cai S, Lv Q, et al. Lamin B receptor plays a role in stimulating nuclear envelope production and targeting membrane vesicles to chromatin during nuclear envelope assembly through direct interaction with importin beta. J Cell Sci 2007; 120:520-530.

29 Lu X, Shi Y, Lu Q, et al. Requirement for lamin B receptor and its regulation by importin \{beta\} and phosphorylation in nuclear envelope assembly during mitotic exit. $J$ Biol Chem 2010; 285:33281-33293.

30 Laskey RA, Mills AD, Philpott A, Leno GH, Dilworth SM, Dingwall C. The role of nucleoplasmin in chromatin assembly and disassembly. Philos Trans R Soc Lond B Biol Sci 1993; 339:263-269; discussion 268-269.

31 Philpott A, Leno GH. Nucleoplasmin remodels sperm chromatin in Xenopus egg extracts. Cell 1992; 69:759-767.

32 Lu Z, Zhang C, Zhai Z. Nucleoplasmin regulates chromatin condensation during apoptosis. Proc Natl Acad Sci USA 2005; 102:2778-2783.

33 Rice P, Garduno R, Itoh T, Katagiri C, Ausio J. Nucleoplasmin-mediated decondensation of Mytilus sperm chromatin. Identification and partial characterization of a nucleoplasminlike protein with sperm-nuclei decondensing activity in Mytilus californianus. Biochemistry 1995; 34:7563-7568.

34 Yang CH, Lambie EJ, Snyder M. NuMA: an unusually long coiled-coil related protein in the mammalian nucleus. $J$ Cell 
Biol 1992; 116:1303-1317.

35 Merdes A, Ramyar K, Vechio JD, Cleveland DW. A complex of NuMA and cytoplasmic dynein is essential for mitotic spindle assembly. Cell 1996; 87:447-458.

36 Philpott A, Leno GH, Laskey RA. Sperm decondensation in Xenopus egg cytoplasm is mediated by nucleoplasmin. Cell 1991; 65:589-578.

37 Goldfarb DS, Corbett AH, Mason DA, Harreman MT, Adam SA. Importin a: a multipurpose nuclear-transport receptor. Trends Cell Biol 2004; 14:505-514.

38 Banuelos S, Hierro A, Arizmendi JM, Montoya G, Prado A, Muga A. Activation mechanism of the nuclear chaperone nucleoplasmin: role of the core domain. J Mol Biol 2003; 334:585-593.

39 Hierro A, Arizmendi JM, Banuelos S, Prado A, Muga A. Electrostatic interactions at the C-terminal domain of nucleoplasmin modulate its chromatin decondensation activity. Biochemistry 2002; 41:6408-6413.

40 Dingwall C, Dilworth SM, Black SJ, Kearsey SE, Cox LS, Laskey RA. Nucleoplasmin cDNA sequence reveals polyglutamic acid tracts and a cluster of sequences homologous to putative nuclear localization signals. EMBO J 1987; 6:69-74.

41 Dingwall C, Sharnick SV, Laskey RA. A polypeptide domain that specifies migration of nucleoplasmin into the nucleus. Cell 1982; 30:449-458.

42 Wiese C, Wilde A, Moore MS, Adam SA, Merdes A, Zheng Y. Role of importin- $\beta$ in coupling Ran to downstream targets in microtubule assembly. Science 2001; 291:653-656.

43 Gruss OJ, Carazo-Salas RE, Schatz CA, et al. Ran induces spindle assembly by reversing the inhibitory effect of importin $\alpha$ on TPX2 activity. Cell 2001; 102:83-93.

44 Bilbao-Cortés D, Hetzer M, Längst G, Becker PB, Mattaj IW. Ran binds to chromatin by two distinct mechanisms. Curr Biol 2002; 12:1151-1156.

45 Hughes M, Zhang C, Avis JM, Hutchison CJ, Clarke PR. The role of the ran GTPase in nuclear assembly and DNA replication: characterisation of the effects of Ran mutants. J Cell Sci 1998; 111:3017-3026.

46 Hartl P, Olson E, Dang T, Forbes DJ. Nuclear assembly with lambda DNA in fractionated Xenopus egg extract: an unexpected role for glycogen in formation of a higher order chromatin intermediate. J Cell Biol 1994; 124:235-248. 